\title{
Health policy in Europe: factors critical for success
}

\author{
Large health gains could be made if all countries in Europe adopted the health policies of the best \\ performing country. Johan P Mackenbach, Marina Karanikolos, and Martin McKee examine the \\ differences between countries and the reasons behind them
}

\author{
Johan P Mackenbach professor of public health ${ }^{1}$, Marina Karanikolos research associate ${ }^{2}$, Martin \\ McKee professor of European public health ${ }^{2}$
}

${ }^{1}$ Department of Public Health, Erasmus MC, PO Box 2040, 3000 CA Rotterdam, Netherlands; ${ }^{2}$ European Observatory on Health Systems and Policies, London School of Hygiene and Tropical Medicine, London WC1H 9SH, UK

Over recent decades, policies in areas such as tobacco and alcohol control, early detection of hypertension and cancer, and child and road safety have made important contributions to improvements in population health in Europe. This progress has, however, been uneven, and some countries lag considerably behind the front runners. ${ }^{12}$ While some of these variations reflect differences in available resources, others reflect differences in willingness to take action, as illustrated by the fact that neighbouring countries in similar economic conditions sometimes have very different outcomes.

\section{Major successes mirrored by large failures}

Over the past 40 years, European countries have followed very different health trajectories. This can most easily be seen in the area of life expectancy, which has increased almost continuously in the Nordic countries, the United Kingdom and Ireland, and continental and Mediterranean Europe. Yet in central and eastern Europe $^{3}$ and the former Soviet Union, ${ }^{4}$ it was already stagnating by 1970 and began to improve only in the 1990s or later (fig $1 \Downarrow)$. The differences are due to diverging trends in rates of death from a wide range of causes, many of which have become amenable to interventions within and outside the healthcare sector, such as lung, cervical, and breast cancer; ischaemic heart and cerebrovascular disease; liver cirrhosis; maternal and infant mortality; and road traffic and other injuries.

Changes in mortality from a particular cause almost always reflect the interplay of a wide range of factors, only some of which are within the control of individuals and governments. Although it is often not possible to determine the quantitative contribution of purposive action, there is compelling evidence that declines in mortality from causes amenable to intervention are partly due to the implementation of effective health policies (box 1, web appendix). In many western European countries, lung cancer mortality is falling, particularly among men, as a delayed response to the tobacco control efforts over the past decades that reduced the prevalence of smoking. ${ }^{5}$ Similarly, declining mortality from cervical and, more controversially, ${ }^{6}$ breast cancer partly reflects the introduction of population based screening..$^{7-9}$ Lifestyle improvements (less smoking, dietary change) have contributed to falls in ischaemic heart and cerebrovascular disease, as have increased detection and treatment of hypertension and improvements in medical care. ${ }^{1011}$ In some countries, more stringent alcohol control measures have led to reduced alcohol consumption and falling mortality from liver cirrhosis (while conversely their relaxation has been followed by increased mortality). ${ }^{12}$ The falls in maternal and infant mortality can be partly attributed to improved access to contraception and safe abortion, prenatal care, prevention of cot death, and other measures related to mother and child health. ${ }^{13}$ In many countries, improved road traffic safety has greatly reduced deaths from road traffic injuries despite increased road usage. ${ }^{14} 15$

The scale of these population health advances can be gauged by looking at the numbers of deaths that would have occurred in 2009 in Europe as a whole if death rates had remained at their 1970 levels (table $1 \Downarrow$ ). For example, we calculate that 351000 deaths from ischaemic heart disease and 355000 deaths from cerebrovascular disease among men have been averted and, had this not occurred, mortality from these diseases in 2009 would have been $42 \%$ and $86 \%$ higher, respectively. 


\section{Box 1: Assessment of the evidence}

Our analysis covered 10 areas of health policy that were identified as having contributed to major population health gains in the past four decades in many European countries: tobacco; alcohol; food and nutrition; fertility, pregnancy, and childbirth; child health; infectious diseases; detection and treatment of hypertension; cancer screening; road safety; and air pollution. For each of these areas we carried out literature searches for evidence on the effectiveness of potentially relevant policies. ${ }^{1}$ Existing systematic reviews and overviews prepared for policy advice allowed us to identify specific preventive policies which, if implemented, could have affected population health

We then collected data on the implementation of these policies in different European countries and on their population health effects. We gathered information on a wide range of process and outcome indicators. We distinguished between intermediate outcomes (measuring exposure to health risk, such as smoking prevalence) and final outcomes (measuring effect on health, such as lung cancer mortality). We aimed for two or three indicators for each area of health policy, all measured around the year 2008.

In a further quantitative analysis we combined the 27 indicators that were finally selected into a summary score indicating, for each country, its relative success across all areas. This summary score was constructed by determining, for each indicator, whether the country was in the upper, middle, or lower third of the distribution and by taking the difference between the percentage of scores in the upper third and the percentage of scores in the lower third-for example, 13 out of 27 performance indicators (48\%) for the United Kingdom were in the upper third of the European distribution, against 3 out of $27(11 \%)$ in the lower third and therefore its summary score was $37 \%(48 \%-11 \%)$.

We then performed a series of regression analyses in which the single indicators as well as the summary score were related to a number of potential determinants, all measured around the year 2000 to allow for lag times: national income (gross domestic product per capita), ${ }^{37}$ survival/self expression values (score reflecting the degree to which populations' priorities have shifted from basic economic and physical security towards subjective wellbeing, self expression, and quality of life), ${ }^{23}$ democracy (score based on the competitiveness of political participation, constraints on the chief executive, and other aspects of liberal democracy), ${ }^{38}$ government effectiveness (score determined by professionalism of the civil service, functioning of government departments and agencies, absence of corruption, etc.), ${ }^{37}$ left party participation in government (cumulative years of social democratic government since 1960), ${ }^{39}$ and ethnic fractionalisation (population heterogeneity along ethnic, linguistic, and religious lines) ${ }^{24}$

Further details of the evidence of effectiveness of policies in each area can be found in the web appendix, along with a description of the measures used and key analyses. Full details of data, methods, and results have been reported elsewhere. ${ }^{12}$

Falls in mortality from other causes have also been substantial. However, for lung and breast cancer in women, the number of deaths is greater than would have been expected from 1970 rates. Although breast cancer mortality has fallen in the Nordic countries, Britain and Ireland, and continental and Mediterranean Europe, partly in response to breast cancer screening and improvements in therapy, it has risen in central and eastern Europe and the former Soviet Union, which leads to a negative total number of saved lives in Europe as a whole. Enormous variations are also seen for other conditions. For example, among men, mortality from lung cancer has already decreased substantially in the Nordic countries, Britain and Ireland, and continental Europe, but it is still increasing in much of Mediterranean, central, and eastern Europe and the former Soviet Union. If all countries had achieved the age specific mortality rates of Sweden, the country that has the best health policy performance overall, far fewer deaths would have occurred in 2009 in Europe as a whole (box 2).

\section{Factors that are critical for success}

Why have some countries been more successful in pursuing effective health policies than others? Here we should differentiate between the "means" and the "will" to implement health policies. Of course, there must be adequate financial resources. Although health policies vary greatly in cost—and some, such as increased tobacco and alcohol taxation, can generate income-it will inevitably be easier for wealthy countries than poor ones to introduce many policies, especially those based on service provision. It is therefore no surprise that countries with a higher national income generally perform better (fig $2 \Downarrow$ ). However, some countries perform substantially better or worse than their national income seems to allow. For example, among the high income countries in Europe, Sweden does better and Belgium does worse than predicted, and among the middle income countries in Europe Albania does better and Russia does worse than predicted by its economic "means."

In addition to financial means countries must have functioning institutions, providing, among other things, effective government (such as the ability to enact legislation and enforce the law) and a competent public health workforce. Again, these differ greatly between European countries. Many of the countries in central and eastern Europe and the former Soviet Union have relatively low levels of government effectiveness, as reported by international agencies such as the World Bank. ${ }^{16}$

Differences in health policies among countries are probably also determined by differences in "will," including political will ("willingness by decision-makers to act ... with the full and genuine intention to support effective policy solutions collectively developed"17). For health policies to be developed, politicians, policy makers, and professionals must become aware that a problem needs to be solved and that there is a potential solution. This can come about in many ways and often requires the actions of a range of individuals and organisations. ${ }^{18}$

Although governments have responded quickly to many outbreaks of infectious disease, in other policy areas it has taken many years for an issue to be seen as a problem that requires concerted action, especially for behaviours that involve a degree of personal choice, such as smoking and drinking. Often, civil society organisations, professional bodies, and even individuals have had an important role in setting the agenda, as in the case of the British Consensus on Action on Salt \& Health (CASH) ${ }^{19}$ and the paediatricians in the Netherlands who identified the prone sleeping position as a risk factor for cot death. ${ }^{20}$ In some cases, however, delayed action was due partly to the counter efforts of powerful vested interests. The most notorious example is secondhand smoking, where the tobacco industry conducted a major campaign to create confusion about whether exposure was harmful. ${ }^{21}$ Some countries have been more sensitive to lobbying by the tobacco industry than others. ${ }^{22}$

The role of differences in will is apparent not only from simple observation but also from the fact that differences in overall performance between countries are closely associated with the values of a country's population and, specifically, where they lie on a survival/self expression scale. This explanatory factor showed the strongest association with overall policy performance $\left(r^{2}=0.87\right)$ (box 1, web appendix). ${ }^{23}$ The more a population is oriented towards modern self expression values emphasising quality of life, the more successful that country's health policies are. This is consistent with a large body of theory which suggests that once people have sufficient resources not to have to worry about how they will survive from day to day, they can begin to think about how they will invest in their health in the future. This creates the opportunity for health promotion efforts aiming to improve behaviours such as smoking and diet. However, will also seems to depend on a sense of national 


\section{Box 2: Potential years of life lost in excess of those in Sweden, 2009}

Mortality data by cause of death provide a rich source of information about variations in health outcomes among countries. We studied a range of causes of death that have become amenable to prevention, such as lung cancer (tobacco control), cervical cancer (screening), and road traffic injuries (road safety). For each European country we determined the number of potential years of life lost (PYLL) before the age of 85 for each of the selected causes in each country in 2009 (or the latest year for which data were available). We then calculated the PYLL compared with Sweden, which had the best health policy performance in 2009. Using national population numbers by age in 2009 and the age specific mortality rates in Sweden we calculated the number of PYLL that could have been expected to occur in each country if the Swedish mortality rates had applied. This expected number of PYLL in each country was then subtracted from the observed number to calculate the excess PYLL. We illustrate the results for three causes of death (see figures on bmj.com).

Lung cancer-Age standardised death rates vary widely between countries in Europe. Sweden is among the countries with the lowest death rate from lung cancer (both sexes combined), together with Finland, Cyprus, Georgia, and Azerbaijan. In other countries, up to $70 \%$ of PYLL from lung cancer could be avoided if those countries had the death rates of Sweden. Hungary, Serbia, and Poland come out worst on this indicator.

Cervical cancer-Death rates from cervical cancer vary more than 20 -fold between European countries, and Sweden is again among the countries with the lowest death rates, together with Finland, Iceland, the Netherlands, and some Mediterranean countries. Up to $85 \%$ of

PYLL from cervical cancer in other countries could be avoided if they had the death rates of Sweden. In this case, Romania, Moldova, and Lithuania come out worst.

Road traffic injury-Up to $86 \%$ of PYLL from road traffic injury could be avoided if other countries had the death rates of Sweden. Russia, Belarus, and Greece have the worst performance on this indicator.

solidarity. The ability to explain policy performance was enhanced $\left(r^{2}=0.90\right)$ by the inclusion of a measure of ethnic fractionalisation, ${ }^{24}$ whereby ethnically, linguistically, and religiously more homogeneous populations performed better. This is consistent with research showing that divided societies are less willing to invest in collective goods. ${ }^{25}$

\section{Neighbours going in different directions}

Some of these differences come out clearly when we compare neighbouring countries that are similar in many respects but have pursued different health policies. Denmark and Sweden provide a first example. Denmark performs less well than its immediate neighbour Sweden, ${ }^{26}$ and while Sweden performs much better than expected on the basis of its national income, Denmark does not (fig $2 \Downarrow$ ). Denmark's mediocre performance applies to many areas of health policy including tobacco control, alcohol control, iodine deficiency, neonatal and maternal mortality, measles immunisation, and road traffic safety. ${ }^{1}$ Yet in comparative studies of processes and conditions of health policy, Denmark is consistently described as a country with well developed and well resourced policies that are supported by strong legal frameworks and a well functioning public health infrastructure, ${ }^{27}$ and a country with an excellent data infrastructure and a well trained workforce.$^{28}$ It is unlikely, therefore, that Danish governments lack the means to achieve better performance; rather it seems that they lack the will to intervene strongly to counter health risks related to modern lifestyles. An in-depth comparison of health policy documents from the four Nordic countries shows that while the health problems are the same, Finnish, Swedish, and Norwegian documents have a strong emphasis on social relations, living conditions, and participation, while Danish health policy documents focus on individual behaviour, responsibility, and autonomy. ${ }^{29} 30$

In continental Europe, Belgium stands out as an underperformer, in comparison with both its immediate neighbour the Netherlands and with all other countries at a similar level of income (fig $2 \Downarrow$ ). Belgium has a relatively low score on survival/self expression values and also has a relatively high degree of ethnic-linguistic fractionalisation (between the Flemish and Walloon communities), which suggest that part of the explanation for its low performance may be a lack of collective will to tackle health problems. However, it performs worse than expected even after values and ethnic fractionalisation are taken into account, and another possible explanation is that it lacks the means to implement policies: it has a shortage of skilled public health professionals ${ }^{31}$ and effectiveness of the Belgian public health infrastructure is hampered by the split between the Flemish and Walloon communities and the federal government.

In central and eastern Europe, Slovenia is performing relatively well, not only in comparison with other former parts of Yugoslavia (which have gone through a much more disruptive secession process $\mathrm{s}^{32}$ and have lower national incomes) but also in comparison with Hungary. Slovenia is more active than Hungary in tobacco control, has lower death rates from lung cancer and liver cirrhosis (although still high compared with western Europe), does better on iodine deficiency, healthy eating, teenage pregnancy, maternal and infant mortality, and child and road safety. Slovenia has gone through a rapid process of political and economic modernisation since it became independent in 1991 and is the richest of the countries in central and eastern Europe. ${ }^{33}{ }^{34}$ The population has a relatively modern value orientation, as measured on the survival/self expression scale, which is likely to be reflected in its health policy choices.

\section{What is to be done?}

The European experience suggests that, in general, health policies tend to follow national income and to align with the values of their populations, but in some cases, governments seem to be in the lead, doing more than might be expected, while in others they lag behind, doing less. A key question is whether international organisations like the World Health Organization and the European Union can help to bring the poorest performers to the levels of the best? They have shown that they have the will to do so, as set out in, for example, the inspirational Health 2020 strategy recently adopted by the European Region of the WHO. ${ }^{35}$ Clearly international organisations can support mutual learning and exchange of experience but this is unlikely to be enough. Can they provide both the will and the means? In theory, the European Union has the resources to close the health gap between countries-for example, by using the European Structural Funds and the Cohesion Fund, which aim to reduce disparities in terms of income, wealth, and opportunities ${ }^{36}$ In practice, however, it has other priorities and covers only the wealthier part of the European region. Our data show that developing effective mechanisms to close the health gap between all European countries could lead to enormous health gains.

This paper is part of an occasional series prepared in conjunction with the European Observatory on Health Systems and Policies (www. healthobservatory.eu).

We thank Peter Anderson, Ahti Anttila, Béatrice Blondel, Caroline Bollars, Laura Currie, Anna Gilmore, Patrick Goodman, Susann 


\section{Key messages}

Some of the health disparities between European countries result from differences in their health policies Differences in health policy performance are not only due to in financial resources but also reflect differences in will Universal adoption of effective health policies throughout Europe would lead to enormous health gains This would require an inspirational vision for health in Europe and the resources to make it a reality

Henschel, Babak Khoshnood, José Martin-Moreno, Andrew McCulloch, Sylvia Medina, Francesco Mitis, Ionela Petrea, Ralf Reintjes, Liselotte Schäfer Elinder, Dinesh Sethi, Ingrid Wolfe, and Jennifer Zeitlin for their invaluable contributions to the book Successes and Failures of Health Policy in Europe: Four Decades of Diverging Trends and Converging Challenges. We also thank the Rockefeller Foundation for hosting JPM and MM during a residency in their Bellagio Centre and the European Observatory on Health Systems and Policies for financial support.

Contributors and sources: This article is based on work undertaken by JPM and MM within the framework of the book Successes and Failures of Health Policy in Europe. ${ }^{1}$ MK provided help with quantitative analysis. JPM wrote the first draft of this paper, and this was revised by MM and MK. All authors approved the final version. JPM is guarantor.

Competing interests: All authors have read and understood the BMJ Group policy on competing interests and have no relevant interests to declare.

Provenance and peer review: Not commissioned; externally peer reviewed.

1 Mackenbach JP, McKee M, eds. Successes and failures of health policy in Europe: fou decades of diverging trends and converging challenges. Open University Press, 2013. Mackenbach JP, McKee M. A comparative analysis of health policy performance in 43 European countries. Eur J Public Health (forthcoming)

3 Chenet L, McKee M, Fulop N, Bojan F, Brand H, Hort A, et al. Changing life expectancy in central Europe: is there a single reason? J Public Health Med 1996;18(3):329-36.

4 Leon DA, Chenet L, Shkolnikov VM, Zakharov S, Shapiro J, Rakhmanova G, et al. Huge variation in Russian mortality rates 1984-94: artefact, alcohol, or what? Lancet 1997:350:383-8.

5 Bray FI, Weiderpass E. Lung cancer mortality trends in 36 European countries: secular trends and birth cohort patterns by sex and region 1970-2007. Int $J$ Cancer 2010;126(6):1454-66.

6 Gotzsche PC, Jorgensen KJ, Zahl PH, Maehlen J. Why mammography screening has not lived up to expectations from the randomised trials. Cancer Causes Control 2012:23:15-21.

7 International Agency for Research on Cancer. Cervix cancer screening. IARC, 2005.

8 Anttila A, Sarkeala T, Hakulinen T, Heinavaara S. Impacts of the Finnish service screening programme on breast cancer rates. BMC Public Health 2008;8:38.

9 Berry DA, Cronin KA, Plevritis SK, Fryback DG, Clarke L, Zelen M, et al. Effect of screening and adjuvant therapy on mortality from breast cancer. N Engl J Med 2005:353:1784-92.

10 Bjorck L, Capewell S, Bennett K, Lappas G, Rosengren A. Increasing evidence based treatments to reduce coronary heart disease mortality in Sweden: quantifying the potential gains. J Intern Med 2011;269:452-67.

11 Bjorck L, Rosengren A, Bennett K, Lappas G, Capewell S. Modelling the decreasing coronary heart disease mortality in Sweden between 1986 and 2002. Eur Heart J 2009;30:1046-56.

12 Anderson P, Møller L, Galea G, eds. Alcohol in the European Union. WHO, 2012

13 Bhutta ZA, Cabral S, Chan CW, Keenan WJ. Reducing maternal, newborn, and infan mortality globally: An integrated action agenda. Int J Gynaecol Obstet 2012;119(supp 1):S13-7
14 Racioppi F. Preventing road traffic injury: a public health perspective for Europe. WHO Regional Office for Europe, 2004

15 European Traffic Safety Council. 2010 road safety target outcome: 100,000 fewer deaths since 2001. 5th Road Safety PIN Report. ETSC, 2011.

16 Berg-Schlosser $\mathrm{D}$. The quality of democracies in Europe as measured by current indicators of democratization and good governance. J Communist Stud Trans Politics 2004:20:28-55.

17 Pagliccia N, Alvarez Perez A. The Cuban experience in public health: does political will have a role? Int J Health Serv 2012;42:77-94

18 Balabanova D, McKee M, Mills A. Good health at low cost 25 years on: what makes a good health system. London School of Hygiene and Tropical Medicine, 2011.

19 MacGregor GA, Sever PS. Salt-overwhelming evidence but still no action: can a consensus be reached with the food industry? CASH (Consensus Action on Salt and Hypertension). BMJ 1996:312:1287-9.

20 McKee M, Fulop N, Bouvier P, Hort A, Brand H, Rasmussen F, et al. Preventing sudden infant deaths-the slow diffusion of an idea. Health Policy 1996;37:117-35.

21 Diethelm PA, Rielle JC, McKee M. The whole truth and nothing but the truth? The research that Philip Morris did not want you to see. Lancet 2005;366:86-92.

22 Gruning T, Gilmore AB, McKee M. Tobacco industry influence on science and scientists in Germany. Am J Public Health 2006;96:20-32.

23 Inglehart R. Globalization and postmodern values. Washington Quarterly 2000:23:215-28

24 Norwegian Social Science Data Services. Fractionalization data2011. www.nsd.uib.no/ macrodataguide/set.html?id=16\&sub=1.

25 Alesina A, Glaeser EL. Fighting poverty in the US and Europe: a world of difference. Oxford University Press, 2004

26 Chenet L, Osler M, McKee M, Krasnik A. Changing life expectancy in the 1980s: why was Denmark different from Sweden? J Epidemiol Community Health 1996;50:404-7.

27 Allin S, Mossialos E, McKee M, Holland W. Making decisions on public health: a review of eight countries. European Observatory of Health Systems, 2004.

28 Brand $\mathrm{H}$, Aluttis $\mathrm{C}$. Reviewing public health capacity in the EU. Final report. Maastricht University, 2011.

29 Vallgarda S. Addressing individual behaviours and living conditions: four Nordic public health policies. Scand J Public Health 2011:39(suppl 6):6-10.

30 Vallgarda S. Public health policies: a Scandinavian model? Scand J Public Health 2007;35(2):205-11.

31 Ritsatakis A, Makara P. Gaining health. Analysis of policy development in European countries for tackling noncommunicable dise. World Health Organization, 2009.

32 Kunitz SJ. The making and breaking of Yugoslavia and its impact on health. Am J Public Health 2004:94:1894-904.

33 Albreht T, Klazinga NS. Restructuring public health in Slovenia between 1985 and 2006 Int J Public Health 2008;53:150-9.

34 Albreht T, Turk E, Toth M, Ceglar J, Marn S, Pribakovic Brinovec R, et al. Slovenia. Health system review. Health Syst Trans 2009;11(3).

35 World Health Organization. Health 2020: a European policy framework supporting action across government and society for health and well-being. WHO Regional Officie for Europe, 2012.

36 Rodriguez-Pose A, Fratesi U. Between development and social policies: the impact of European structural funds in objective 1 regions. Regional Stud 2004;38:97-113.

37 World Bank. Word development indicators. 2012. http://data.worldbank.org/data-catalog/ world-development-indicators.

38 Polity IV database. Polity IV project: political regime characteristics and transitions, 1800-2009. Center for Systemic Piece, 2010.

39 Armingeon K, Weisstanner D, Engler S, Potolidis P, Gerber M, Leimgruber P. Comparative Political Data Set I 1960-2009. 2011.

Accepted: 7 January 2013

Cite this as: BMJ 2013;346:f533

(c) BMJ Publishing Group Ltd 2013 


\section{Table}

Table 1| Deaths saved by health policy interventions in 2009, Europe as a whole

\begin{tabular}{|c|c|c|c|c|}
\hline \multirow[b]{2}{*}{ Cause of death } & \multicolumn{2}{|c|}{ Observed deaths } & \multicolumn{2}{|c|}{ No $(\%)$ of averted deaths* } \\
\hline & Men & Women & Men & Women \\
\hline Infectious diseases (0-85 years) & 57925 & 21537 & $28207(49)$ & $14235(66)$ \\
\hline Lung cancer & 273904 & 91510 & $17223(6)$ & $-44514(-49)$ \\
\hline Breast cancer & - & 129396 & - & $-16355(-13)$ \\
\hline Cervical cancer & - & 20703 & - & $14394(70)$ \\
\hline Ischaemic heart disease & 837733 & 870405 & $351406(42)$ & $372010(43)$ \\
\hline Cerebrovascular disease & 412152 & 608558 & $354806(86)$ & $507621(83)$ \\
\hline Liver cirrhosis & 110286 & 55594 & $29702(27)$ & $13625(25)$ \\
\hline Infant mortality & 26706 & 20471 & $85172(319)$ & $61881(302)$ \\
\hline Maternal mortality & - & 950 & - & $2523(266)$ \\
\hline Road traffic injuries & 60733 & 19620 & $73144(120)$ & 23394 (119) \\
\hline Other external causes (1-19 years) & 6422 & 2569 & $7361(115)$ & $2641(103)$ \\
\hline All selected causes of death & 1785861 & 1841313 & $947021(53)$ & $951453(52)$ \\
\hline
\end{tabular}

*Averted deaths estimated by taking each country's age and sex specific death rates in 1970 (or least recent available year), multiplying this with each country's age and sex specific population numbers in 2009, and taking the difference between the number of expected deaths thus calculated, and the observed number of deaths in 2009. Data from WHO Mortality Database. 


\section{Figures}

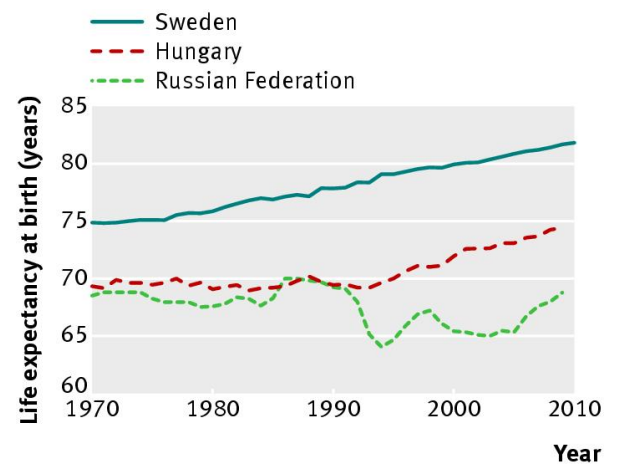

Fig 1 Trends in life expectancy at birth (both sexes combined) in exemplar countries from western Europe (Sweden), central and eastern Europe (Hungary), and the former Soviet Union (Russian Federation)

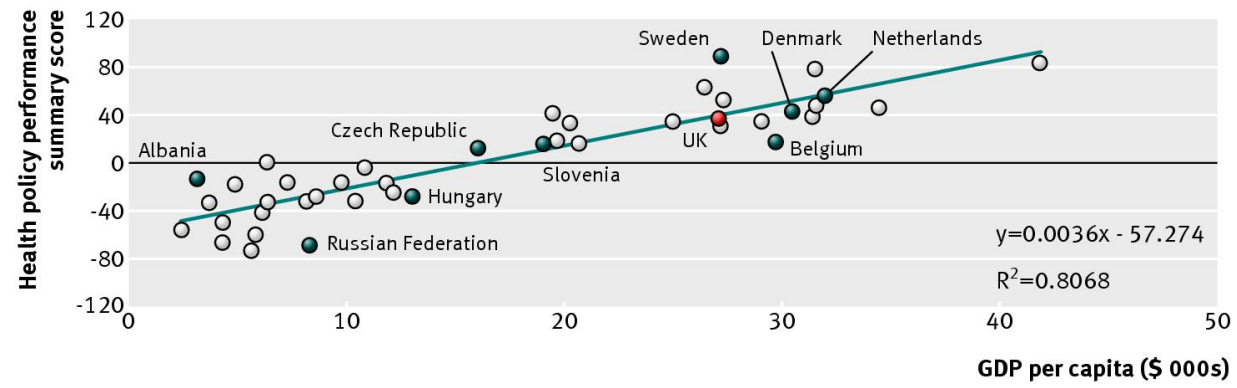

Fig 2 Relation between national income and health policy performance. GDP measured in 2000; health policy performance measured around 2008 (see box 1 for details of calculation). Luxembourg excluded because of outlier status 